\title{
The Synchrony and Cyclicity of Developmental Events
}

\author{
Yumiko Saga \\ Mammalian Development Laboratory, National Institute of Genetics, Yata 1111, Mishima, Shizuoka 411-8540, Japan \\ Correspondence: ysaga@lab.nig.ac.jp
}

\section{SUMMARY}

Many of the morphogenetic processes that occur during development in the mouse are based on cyclic events with defined time intervals, as exemplified by somitogenesis (every $2 \mathrm{~h}$ ), hair cycles (every $25 \mathrm{~d}$ ), and spermatogenesis (every $35 \mathrm{~d}$ ). Among these events, somitogenesis is the most dynamic morphogenetic mechanism showing clear cyclicity during embryogenesis and is therefore a good system with which to review the synchronous and cyclic characteristics of developmental pathways. The metameric properties of the somites underpin the segmental properties along the anterior-posterior (AP) axis of the body. The periodicity of somites is controlled by the so-called segmentation clock operating in the presomitic mesoderm (PSM). This tissue contains the somite precursor cells that exist only during embryonic development. Both theoretical and experimental approaches have contributed to the understanding of the mechanism of somite segmentation. This article focuses on how the segmentation clock functions to organize the collective behavior of cells and how this information is translated into the spatial patterning of segmental somites. The interplay between signaling molecules that provides positional information and the transcription factors that respond to such positional cues are critical to the role of the segmentation clock and are discussed.

\section{Outline}

1 General aspects of somitogenesis

2 The temporal control of somitogenesis via the segmentation clock

3 Translation of clock information
4 The mechanism to initiate and terminate cyclic gene expression: How is the somite number determined?

5 Concluding remarks

References

Editors: Patrick P.L. Tam, W. James Nelson, and Janet Rossant

Additional Perspectives on Mammalian Development available at www.cshperspectives.org

Copyright (C 2012 Cold Spring Harbor Laboratory Press; all rights reserved; doi: 10.1101/cshperspect.a008201

Cite this article as Cold Spring Harb Perspect Biol 2012;4:a008201 
In the early stages of vertebrate development, just after gastrulation, the body is primarily composed of head and tail structures. The intermediate part of the body is subsequently filled with repeat blocks of cells called somites, in a process known as somitogenesis (Fig. 1). The primitive streak and the tail bud at later developmental stages are sources of new cells that comprise the presomitic mesoderm (PSM). These cells have mesenchymal properties and are laid down on both sides of the neural tube (Pourquie 2003). The presomitic mesoderm is then sequentially subdivided into blocks of epithelial cells to form somites, progressively from the anterior end of the PSM. The time required for individual somite formation and the number of somites formed differs in each species (Gomez et al. 2008; Gomez and Pourquie 2009). In mice, this time frame is about $2 \mathrm{~h}$ commencing on embryonic day 8 (E8.0) and continues to E13.5 leading to the formation of about 65 somites (Saga and Takeda 2001). The somite differentiates into three distinct cell lineages to produce the adult tissues. These are the dermatome (dermis), myotome (skeletal muscle), and sclerotome (vertebral bones) (Saga and Takeda 2001). The initial segmental border is defined when the cells are still in the PSM. In addition to the border between each somite, the sclerotome is subdivided into rostral and caudal halves to generate different vertebral components, a process referred to as resegmentation (Goldstein and Kalcheim 1992). Importantly, this rostral-caudal boundary is predetermined when the somite is born. Thus, the properties of the somites are defined when the cells are still in an unsegmented structure, i.e., as PSM cells. The most intriguing phenomenon during somitogenesis is the formation of clear straight segmental or intersomitic borders across the dorso-ventral axis. This kind of coordinated cell behavior cannot be achieved without synchrony among the PSM cells. In this article, the molecular mechanisms underlying the formation and regulation of synchrony and cyclicity during somitogenesis are discussed with a particular focus on the mouse embryo, but with reference also to other vertebrate systems.

\section{GENERAL ASPECTS OF SOMITOGENESIS}

\subsection{Derivation of the Paraxial Mesoderm during Embryogenesis}

The origin of the somites is the paraxial mesoderm, which is derived from the epiblast during gastrulation. The paraxial mesoderm is bilaterally located on both sides of the midline structures, neural tube and axial mesoderm. After formation of the paraxial mesoderm via ingression of the epiblast, the most posterior parts of the tail region maintain their undifferentiated state and retain the potency to generate either the neural tube or paraxial mesoderm. The Wnt signaling molecules and a T-box transcription factor are implicated in these fate decision processes (Fig. 1A). In the absence of the Wnts (Wnt1 and Wnt3a) or of Tbx6, cells choose the neural tube fate over the paraxial mesoderm, which results in a triple neural tube formation (Chapman and Papaioannou 1998; Yamaguchi et al. 1999). Recently, it has been reported that the Tbx6-dependent regulation of Sox 2 determines the fate of the axial stem cells (Takemoto et al. 2011). Paraxial mesoderm-specific misexpression of a Sox 2 transgene in wild-type mouse embryos results in ectopic neural tube development. Thus, Tbx6 may repress Sox 2 and thereby inhibit neural development, an essential step for the specification of the paraxial mesoderm from the axial stem cells. Hence, the tail bud region acts as a signaling center for normal mesodermal tissues including somites.

\subsection{The Derivation of the PSM and Somite Properties Provide a Base for Metameric Structures}

The paraxial mesoderm derived from the tail bud shows mesenchymal and immature characteristics as compared with the mature somite, and is thus referred to as the PSM. The tail bud provides a stem cell-like population supplying emerging new cells at the posterior end of the PSM, while cells are pushed anteriorly and finally bud off as a somite from the anterior part of the PSM. This is accompanied by a mesenchymal-epithelial transformation. The somites therefore consist of spherical epithelial cell masses that differentiate into dermis, muscle, and skeleton according to their position within the somite (Fig. 1B). The most striking feature of somite formation is the periodic generation of metameric structures. The human body is composed of segmental units, although this is not obvious from its external structure. Internally, these are easily recognizable. The most prominent structures in this regard are the vertebra and ribs, which are directly derived from somites. The nervous system and vasculature networks also exist in tandem and the major networks are segmental. These structures are established through the behavior of precursor cells. Because the neural crest cells derived from the dorsal part of the neural tube migrate laterally through the rostral compartment of the somite only and never enter the caudal half, the metameric arrangement of the peripheral nervous system is necessarily determined by the metameric nature and arrangement of the somites (BronnerFraser 1986; Teillet et al. 1987; Keynes and Stern 1988). This differential cell behavior reflects the different gene expression patterns between the rostral and caudal halves of the somites (Fig. 2). The initial vascular network is also 
A

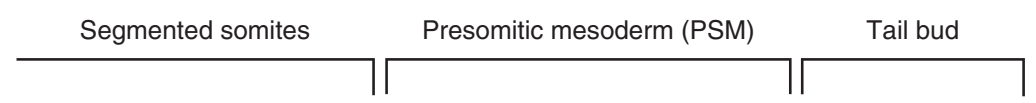

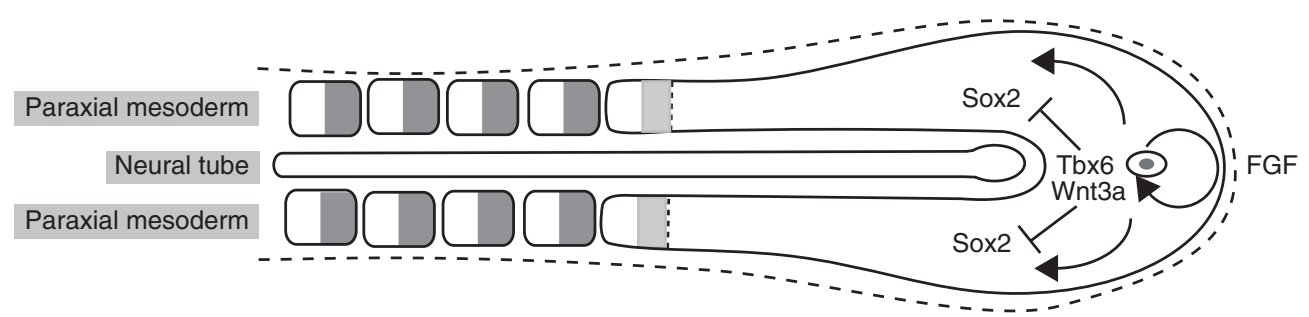

B

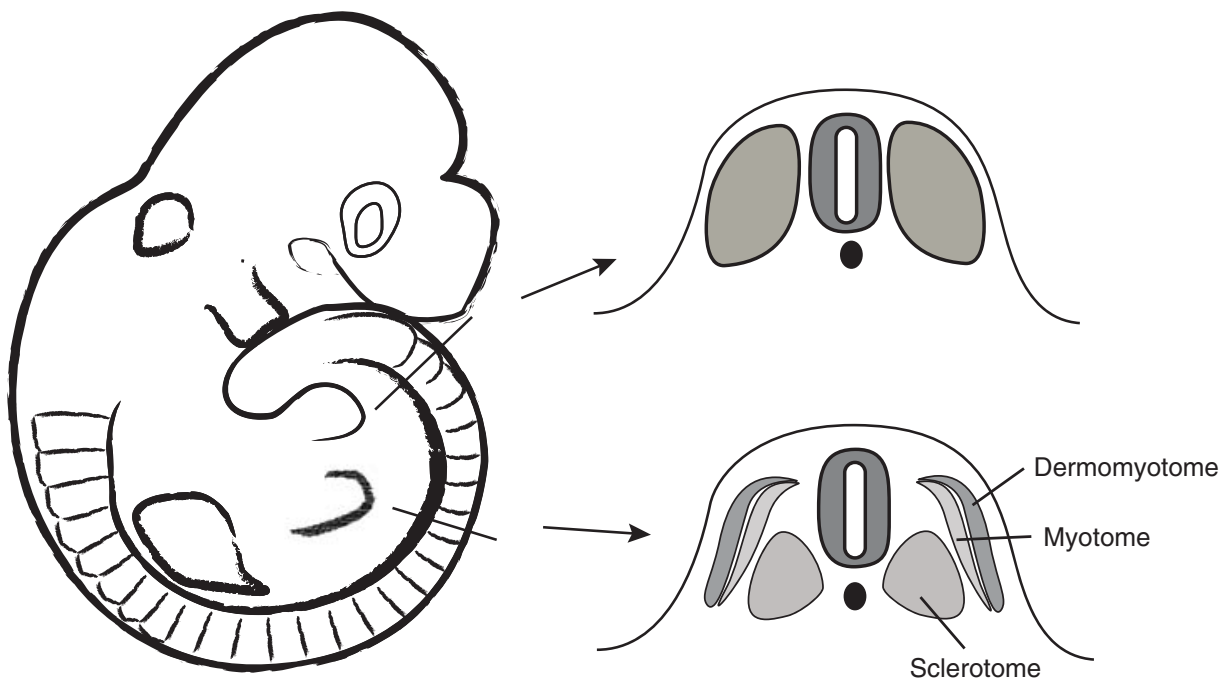

C

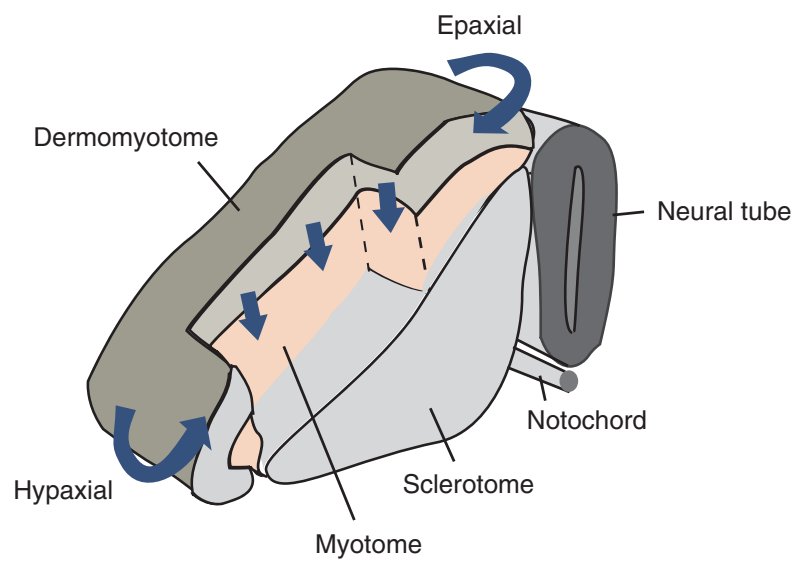

Figure 1. General description of somitogenesis. (A) A schematic representation of somitogenesis. The tail bud contains a stem cell population that gives rise to either the paraxial mesoderm or neural tube compartment. Wnt3a and Tbx6 promote paraxial mesoderm formation, whereas cells expressing Sox 2 choose a neural fate. Paraxial mesodermal cells maintain their immature state before the segmental border is formed and are referred to as the presomitic mesoderm (PSM). Cells located at the anteriormost part of the PSM are ready to form the next somite that is separated into two compartments with rostral and caudal properties. (B) After budding off from the PSM, somites start to differentiate into dermomyotome and sclerotome according to the signals along the dorsal-ventral axis. $(C)$ Different myotomal compartments derived from different regions of the dermomyotome contribute to different parts of the body muscle. The major signals come from the neural tube, notochord, and epidermis. 


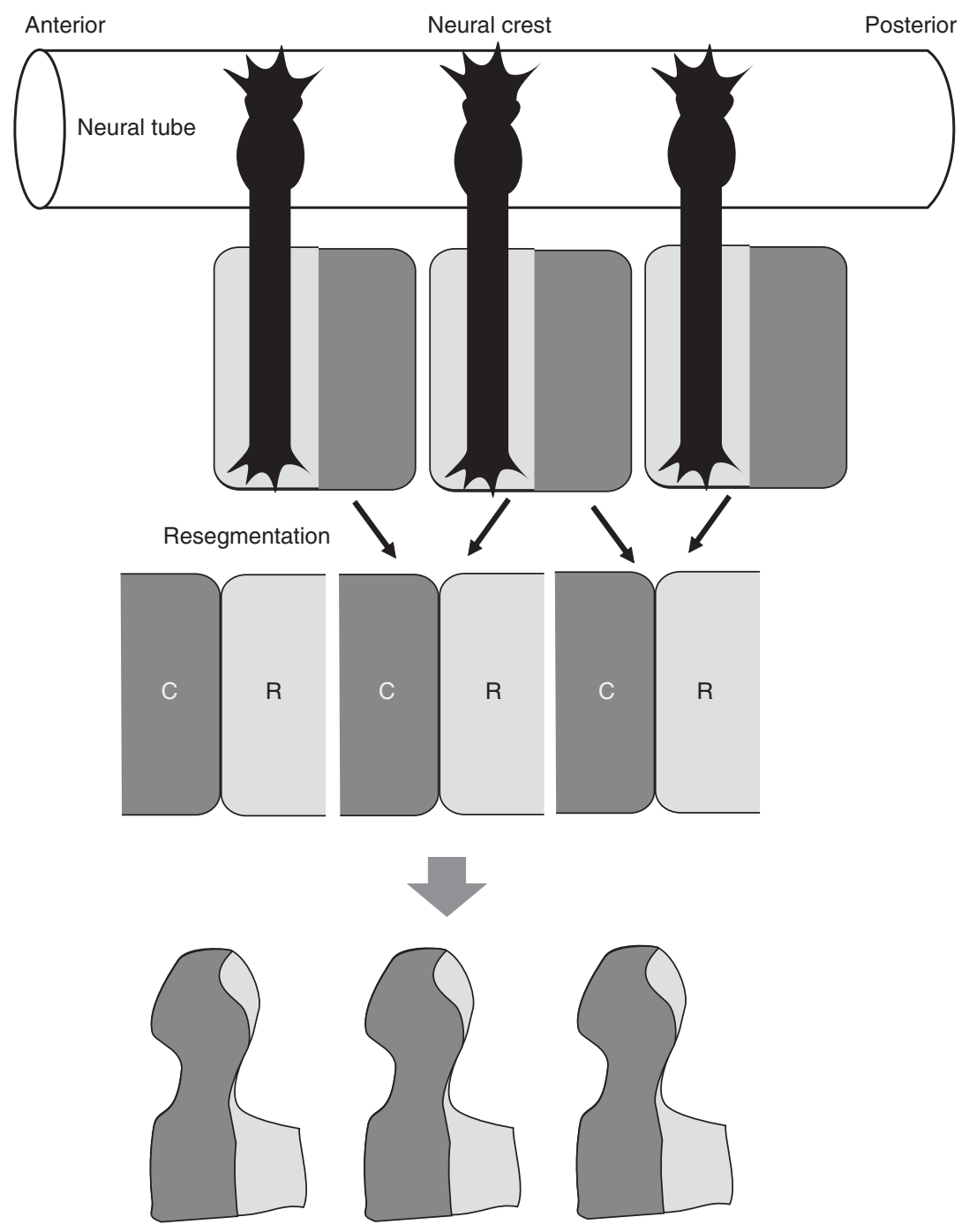

Figure 2. Establishment of the segmental pattern of the peripheral nervous system and vertebra. The peripheral neurons are derived from neural crest cells delaminated from the dorsal part of the neural tube. The neural crest cells migrate laterally only through the rostral compartment of a somite, by which the segmental network is established. The rostral and caudal halves of somites segregate, and re-fuse with their neighboring halves to form vertebrae, a phenomenon known as "resegmentation." R, rostral compartment; C, caudal compartment.

dependent on the somite structures because intersomitic vessels are formed and established in conjunction with somitogenesis.

\subsection{Lineage of Somitic Cells and Cell Differentiation (Dorso-Ventral Patterning)}

Once epithelial somites are generated, the somites are patterned in response to signals from the surrounding tissues into distinct compartments giving rise to different cell lineages. The ventromedial somite cells lose their epithelial properties to form the mesenchymal sclerotome, expressing transcriptional regulators such as Pax1 and Pax9 under the influence of sonic hedgehog and noggin from the midline notochord and floor plate (Fan and Tessier-Lavigne 1994; McMahon et al. 1998; Furumoto et al. 1999). The sclerotome, together with the notochord, subsequently differentiates into the vertebral column and ribs. The dorsal somite, known as the dermomyotome, remains an epithelial sheet under the control of Wnts expressed from the dorsal neural tube and surface ectoderm. Slightly later, cells delaminate from the dermomyotome edges and migrate underneath it to form a third compartment, the myotome, located between the dermomyotome and sclerotome. 
As the somite matures, the somitic compartments are further divided into subdomains with unique fates (Fig. $1 \mathrm{C})$. At the dorsomedial edge or lip (DML) of the dermomyotome, cells migrate underneath to generate the epaxial myotome, which then differentiates rapidly into back muscle. Central dermomyotome cells de-epithelialize to form the dorsal dermis, and at the limb bud levels, cells delaminate from the ventrolateral lip (VLL) of the dermomyotome to migrate into the lateral plate mesoderm, where they develop into limb and limb girdle muscle. At the interlimb levels, the cells from the VLL of the dermomyotome translocate underneath, producing the hypaxial myotome. The ventrolateral dermomyotome and hypaxial myotome invade the lateral plate mesoderm together as a somitic bud, from which the body wall and abdominal muscle emerge. Finally, within the sclerotome, the ventromedial cells give rise to the vertebral bodies, intervertebral discs and proximal ribs; the lateral cells, to the neural arches and distal ribs; and the dorsomedial cells, to the spinous processes (Brand-Saberi and Christ 2000; Brent and Tabin 2002).

\subsection{Regionalization along the AP Axis}

The vertebrate body is composed of domains (cervical, thoracic, lumbar, sacral, and caudal regions) that show different identities. These identities are defined in the tail bud region, which is controlled by Hox gene activation (Wellik 2007). It has been shown that Hox genes are involved in the timing of the ingression of paraxial mesoderm precursors into the primitive streak (Iimura and Pourquie 2006). Cells expressing a greater number of $5^{\prime}$ Hox genes ingress at a later stage than those expressing more $3^{\prime}$ Hox genes and would thus be positioned more posteriorly along the AP axis (Fig. $3)$. This mechanism results in a collinear Hox gene expression profile along the AP axis (Iimura et al. 2007). The expression of particular sets of Hox genes has been suggested to establish each somite identity and thus define later vertebral identities (Carapuco et al. 2005; Deschamps and van Nes 2005; Wellik 2007). The phenotypes that arise from loss- and gain-of-function mutations in mouse Hox genes have revealed that the spatiotemporally controlled expression of these genes is critical for the correct morphogenesis

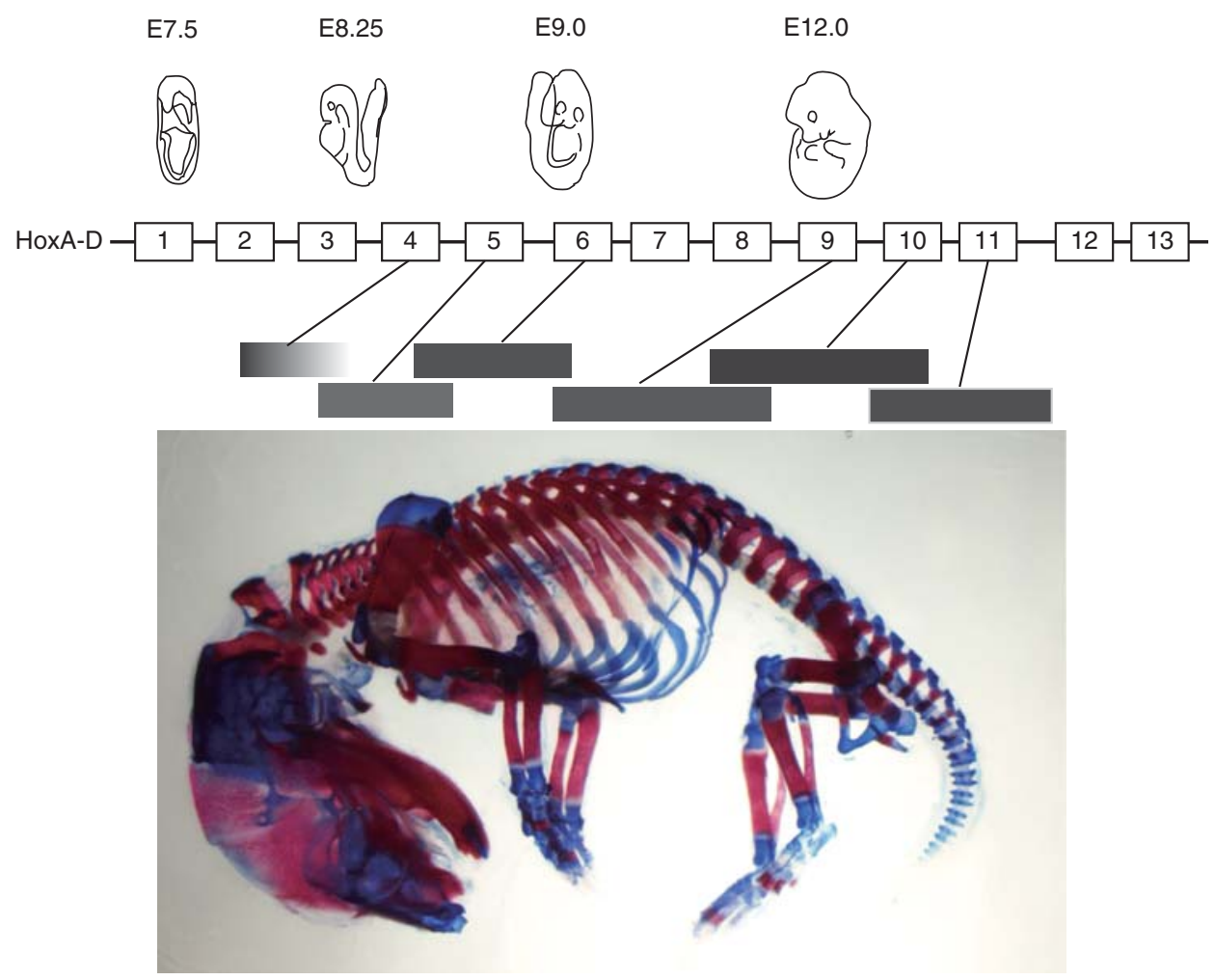

Figure 3. Identity of the segmental regions linked to Hox gene expression: spatiotemporal collinearity. The onset of Hox gene expression is coupled with the growth and elongation of the embryonic axis. Thus, Hox paralogous genes activated during early embryogenesis show clear anterior limits in their expression pattern. The phenotypes of Hox paralogous mutants thus show regional specificity reflecting this expression pattern. The affected regions observed in paralogous mutants are schematically indicated by adjacent bars. 
of embryonic axial structures. For example, simultaneous inactivation of all three Hox paralogous group 10 genes results in mice in which the prospective lumbo-sacral region acquires thoraciclike characteristics whereby these mutant vertebrae display associated ribs all along the thoracolumbar region (Wellik and Capecchi 2003).

\section{THE TEMPORAL CONTROL OF SOMITOGENESIS VIA THE SEGMENTATION CLOCK}

\subsection{The Clock and Wavefront Model (Classical Model)}

Because of the requirement that a specific number of somites forms in a given time period, it is reasonable to predict that somite formation is under tight temporal control. This enigmatic system has been the focus of much speculation among biological theorists and is partly why the socalled "clock and wavefront model" was proposed some time ago in the absence of any molecular information (Cooke and Zeeman 1976). This theoretical model encompasses two components: an oscillator (clock) that measures time and determines the period for somite formation (Fig. 4 ), and spatial information (wavefront), which governs the maturation of the PSM into somites and is defined at a constant distance from the posterior end of the tail bud. The wavefront regresses in an anterior to posterior direction

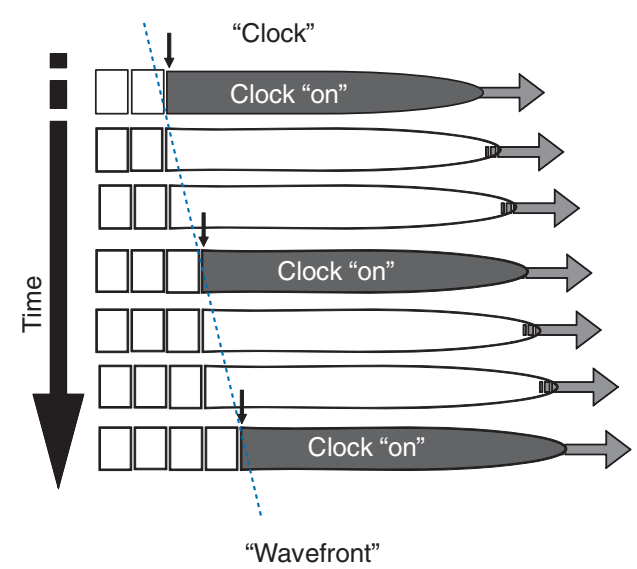

Figure 4. The concept of the "clock and wavefront model." The simple clock and wavefront model explains how each somite is produced with regular timing and spacing. The clock of PSM cells shows either an "on" or "off" state at regular intervals and this oscillates in each cell. The wavefront is defined by the constant distance from the posterior end of the PSM and regresses at a constant speed via posterior elongation. Segmentation takes place when clock of cells in the wavefront adopts an "on" state. During the "off" state, the wavefront regresses with posterior elongation. In the embryo, the clock is turned on at the tail bud and commences oscillation. The sequential initiation of the clock results in the production of a time difference in the on/off state in each PSM cell along the anterior-posterior (AP) axis, which generates a wave pattern of clock gene expression (see also Fig. 6A). and sweeps along the body axis in concert with the extension of the trunk and tail. The activity of the wavefront is gated by the clock. Hence a somite forms only when the wavefront encounters a group of cells in which the clock is in an "on" state (Fig. 4). In this model also, the size of each somite is determined by the speed of the wavefront regression, whereas the rate of somite formation is controlled by the frequency of the oscillator.

\subsection{Molecular Mechanism Underlying Clock Systems}

The first evidence of the existence of an oscillator that was coupled to somitogenesis was provided by the periodic expression of the mRNA encoding the transcription factor $\mathrm{c}$ hairy (an ortholog of Hes1) in the chicken PSM (Palmeirim et al. 1997). During the formation of each somite, the PSM is swept by a dynamic wave of c-hairy messenger RNA (mRNA) expression. Because these transcriptional oscillations were observed to have the same periodicity as somitogenesis, this phenomenon was proposed to represent the segmentation clock functioning in PSM cells. Subsequently, several other genes showing such a cyclic pattern were identified in fish, frog, and mouse, indicating that the clock mechanism might be conserved in vertebrates. These genes are now referred to as cyclic genes and the vast majority belong to the Notch, Wnt, and fibroblast growth factor (FGF) signaling pathways (Dequeant et al. 2006). The requirement of the Notch-signaling pathway for clock behavior has been documented by mutant mouse analysis. Many Notch pathway genes including the receptors and ligands, modifiers of Notch receptors and ligands, and their target genes have been shown to be expressed during the critical steps of somitogenesis, and mutations show defects in different aspects of the process (Fig. 5; Table 1).

After the identification of clock genes, many theoretical models were proposed for the operation of cyclic gene oscillations during somitogenesis. Beginning with the work of Lewis (2003), much attention was directed toward models involving the negative regulation of mRNA transcription by protein products, with delays in transcription and translation resulting in oscillations with periods defined, for the most part, by the total delay in the system. Such models have assumed the following form:

$$
\begin{gathered}
d p / d t=a m(t-T p)-b p(t), \\
d m / d t=f[p(t-T m)]-c m(t),
\end{gathered}
$$

where $m$ denotes the mRNA concentration and $p$ the protein concentration, and $a, b$, and $c$ are positive constants representing protein translation, protein decay, and mRNA 


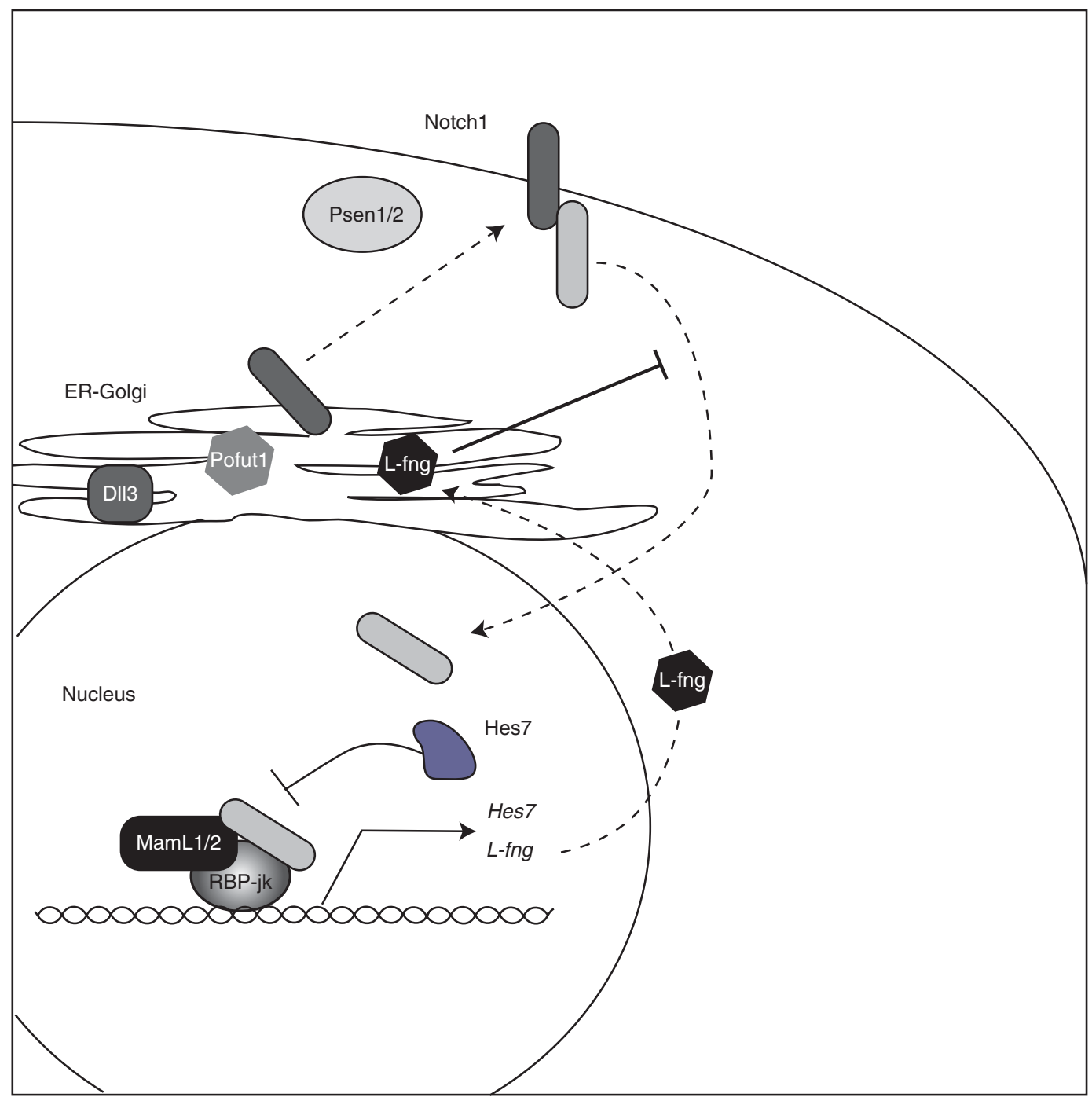

Figure 5. Schematic depiction of the localization and function of the Notch-signaling pathway gene products involved in mouse somitogenesis. Once Notch receptor interacts with the Dll1 expressed in neighboring cells, it is cleaved by Psen $1 / 2$. The cleaved Notch intracellular domain is known as active Notch and enters the nucleus to interact with RBP-jk and MamL1 and thereby activate downstream target genes such as Hes7 and L-fringe. Hes7 is a transcriptional repressor and regulates its own and $L-F n g$ transcription. The extracellular domain of Notch receptor is modified by two glycosyltransferases, Pofut 1 and L-fng, in the ER-Golgi pathway before being exported to the cell membrane. Dll3 is a member of the Notch ligand family, DSL. However, it may function in the cytoplasm, most notably in the Golgi.

decay rates, respectively. Tm and Tp represent the delays in mRNA transcription and protein translation, and the function $f$ represents the negative regulation of mRNA transcription by promoter binding (Lewis 2003). From this basic model of Lewis, many subsequent models were devised to explain several aspects of clock oscillation and to predict mutant phenotypes. Thus far, the Notch-signaling pathway has been shown to be a common mechanism used in several model animals, and a number of proposed models of how this mechanism works in zebrafish and mouse are outlined in the following sections.

\subsubsection{Clock System in Zebrafish}

The cyclic genes identified so far belong to the Notch pathway, and are the Notch downstream targets herl (hairy and enhancer of split-related 1), her7, her11, her12, and her15 (which are homologous to chicken HES1), and also include the Notch ligand DeltaC (Holley et al. 2000; Henry et al. 2002; Oates and Ho 2002). A simple oscillator model has been proposed to explain the oscillation mechanism. The model indicates that oscillations are generated by a negative feedback loop in which the Her1/7 genes are directly 
Table 1. Implication of Notch-signaling pathway genes during mouse somitogenesis

\begin{tabular}{lllll}
\hline Gene & Protein nature & Localization & Phenotype (viability) & References \\
\hline Notch1 & Receptor & Cell membrane, cytoplasm & Embryonic lethal (E11.5) & Conlon et al. 1995 \\
Dll1 & Ligand & Cell membrane, cytoplasm & Embryonic lethal (E11.5) & Hrabe de Angelis et al. 1997 \\
Dll3 & Ligand & Cytoplasm (Golgi?) & Viable, kinked tail & Kusumi et al. 1998 \\
Psen1/2 & $\gamma$ secretase & Cell membrane & Embryonic lethal (E9.5) & Donoviel et al. 1999 \\
Pofut1 & Glycosyltransferase & ER-Golgi & Embryonic lethal (E9.5) & Shi and Stanley 2006 \\
Lunatic fringe & Glycosyltransferase & Golgi & Viable, kinked tail & Evrard et al. 1998; Zhang \\
& & & & and Gridley 1998 \\
Mesp2 & Transcription factor & Nucleus & Die just after birth & Saga et al. 1997 \\
RBP-jk & Transcription factor & Nucleus & Embryonic lethal (E9.5) & de la Pompa et al. 1997 \\
Mastermind1/3 & Transcription factor & Nucleus & Embryonic lethal (E9.5) & Oyama et al. 2011 \\
Hes7 & Transcription factor & Nucleus & Die just after birth & Bessho et al. 2001b \\
\hline
\end{tabular}

Because all mutants show defective somitogenesis, the viability is indicated as the phenotype.

repressed by their own protein products. In addition, the model takes into account a defined time delay from the beginning of transcription of the Her gene until the protein product binds to the Her gene promoter (Lewis 2003). This Her1/7 intracellular oscillator was proposed to be linked to an intercellular oscillator involving the Notchsignaling pathway (Horikawa et al. 2006). Her1/7 negatively regulate DeltaC, thus potentially triggering oscillations of this Notch ligand that should, in turn, result in periodic Notch activation in neighboring cells. This coupling provides a basis for maintaining synchrony (see below). The Her 1-Her7 oscillations require the function of Her13.2 that is regulated by FGF signaling (Kawamura et al. 2005). Her13.2 can form a heterodimer with Her1, enhancing the ability of Herl to negatively regulate its own promoter. Thus, although the Her1-Her7 negative feedback loop constitutes the core of the segmentation clock, other signaling pathways may be additionally involved.

\subsubsection{Clock System in Mice}

The first cyclic genes identified in mice are also targets of the Notch-signaling pathway, such as Hes7 and L-fng (Bessho et al. 2001a; Cole et al. 2002). Furthermore, periodic activation of Notch signaling was detected in the mouse PSM using antibodies raised against the cleaved intracellular domain of the Notch1 receptor, providing direct evidence for the rhythmic activation of the Notch-signaling pathway (Morimoto et al. 2005). As a mechanism to generate gene expression oscillation, a negative feedback mechanism similar to that operating in zebrafish has also been proposed in mice. Hes7, a transcriptional repressor, is initially activated by FGF signaling in the tail bud and then comes under the control of Notch signaling (Fig. 6A) (Niwa et al. 2007). Transcription of the Hes7 gene and accumulation of Hes7 protein occur in a mutually exclusive manner, indicating that Hes7 protein accumulation is substantially delayed relative to Hes7 gene transcription (Fig. 6B,C). Inactivation of Hes7 in mutant mice results in an up-regulation of the Hes7 transcription because of the lack of the Hes7 repressive activity (Bessho et al. 2003). Furthermore, stabilization of Hes7 protein in vivo disrupts Notch-signaling oscillations (Hirata et al. 2004). This negative feedback-mediated oscillatory expression has been mathematically simulated using differential equations. These models have predicted that a delay from transcription to protein expression is required to achieve negative autoregulation. The importance of the processing pathway involved in the transcription and splicing of intronic sequences was recently tested by generating mice carrying the Hes7 locus from which the introns had been removed (Takashima et al. 2011). Hes7 expression did not oscillate in these mice but was steady, leading to severe segmentation defects. These results indicate that introns are indeed required for Hes7 oscillations and highlight the significance of intronic delays in dynamic gene expression (Fig. 6B).

In mice, Hes7 also suppresses another component of the Notch pathway, a gene known as lunatic fringe ( $L-f n g$ ) (Bessho et al. 2003). L-fng is a glycosyltransferase that can modify the extracellular domain of Notch receptors and has been shown to repress Notch activation in both the chick and mouse (Dale et al. 2003; Morimoto et al. 2005). This may elicit Notch activity oscillation within amniotes. However, L-fng oscillation is not observed in zebrafish somitogenesis. The dynamic oscillations of clock genes are visualized in vivo using several reporter activities under the control of Hes1, Hes7, and L-fng promoter or gene cassettes (Masamizu et al. 2006; Aulehla et al. 2008). There reporters faithfully reproduced oscillating expression patterns of these genes in the PSM, which confirmed the periodicity of the clock system. Intriguingly, and unlike zebrafish, some of the target genes of FGF and Wnt signaling pathways also show periodic activity in the mouse PSM, although these signals themselves show a noncyclic 

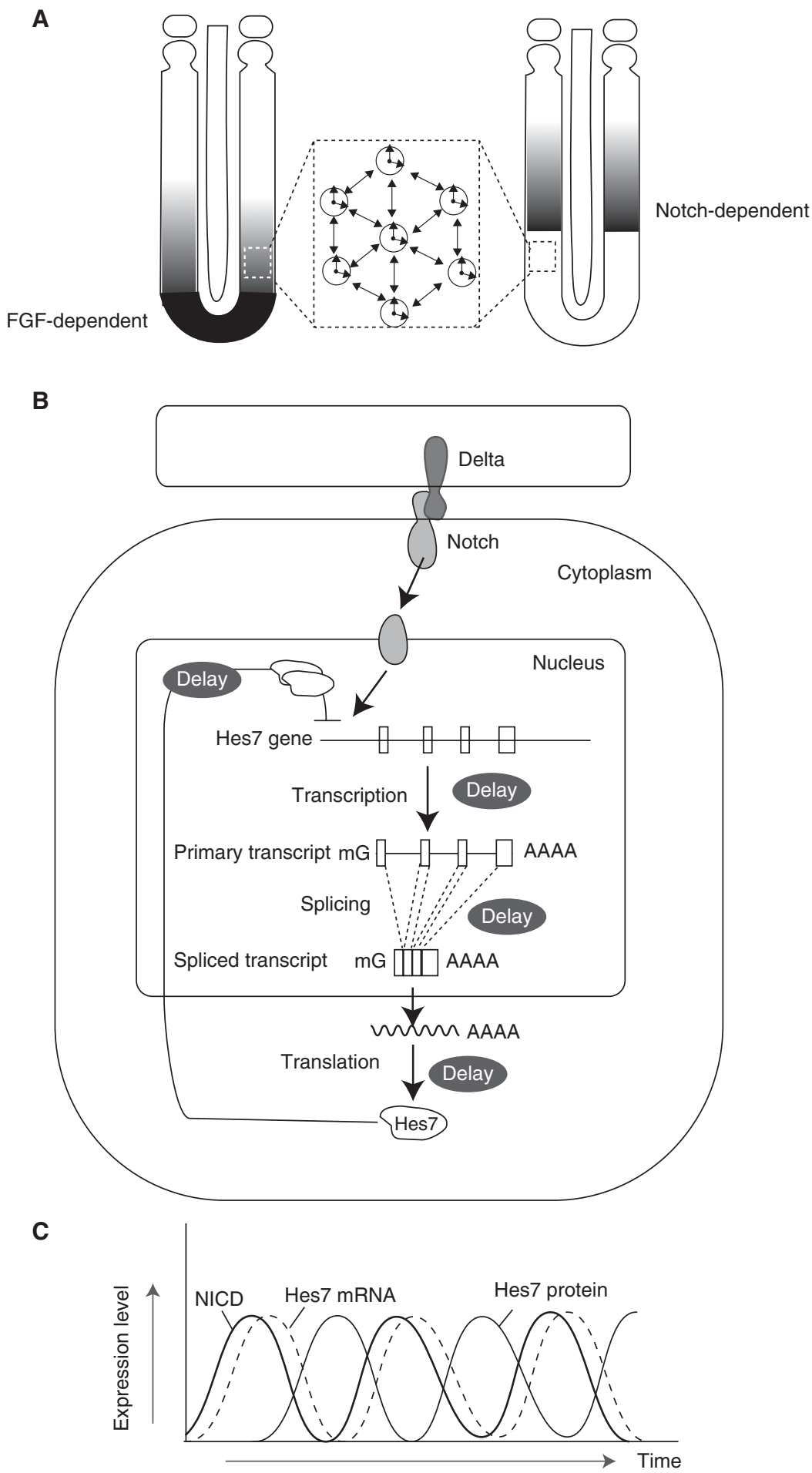

Figure 6. The mechanism generating the Hes7 clock gene oscillation wave during somitogenesis. $(A)$ The expression pattern of Hes 7 at different stages is shown. This expression is activated in the tail bud by an FGF signal but once initiated comes under the control of Notch signaling. The expression levels in individual cells serve as segmentation clocks and the states are synchronized with the neighbors via as yet unknown mechanisms. $(B)$ The primary transcripts of Hes7 are processed in the nucleus and transported to the cytoplasm for translation. The delay in producing mature transcript and protein and the stability of this protein are strictly regulated. $(C)$ Thus the time delay is an important factor in the appropriate operation of the clock during somitogenesis. 
gradient along the AP axis (Dequeant et al. 2006; Dequeant and Pourquie 2008). The significance of oscillation of these signaling pathways remains elusive. In addition, the synchronization mechanism in amniotes has not yet been clarified (see below).

\subsection{Synchronized Oscillation}

The oscillations of clock genes are regulated by the segmentation clock and the underlying molecular mechanism is well established. However, individual PSM cells will behave as noisy autonomous oscillators with a range of different periods if the embryo is dissociated and the gene expression is monitored in individual cells. Even within the embryo, the oscillation phase of individual oscillators must fluctuate owing to developmental noise imposed by stochastic gene expression and active cell proliferation. Hence, there must be a mechanism that synchronizes the oscillation of active genes in the embryo, by which clear waves of gene expression sweep along the AP axis. How this collective behavior is established has been a key question in furthering our understanding of segmentation clocks. It is now known in zebrafish that the segmentation clock behaves as a coupled oscillator, via Notch-dependent intercellular communication (Jiang et al. 2000; Horikawa et al. 2006). Because DeltaC expression is also under the control of the Her1/7 transcriptional repressor and also oscillates, individual cells can communicate with neighboring cells by transmitting Notch signals, which enable a coupling of the oscillations in individual cells. This coupling process plays a crucial role in minimizing the effects of developmental noise to maintain coherent oscillation. In addition, it has been shown that Delta-Notch coupling influences the collective period of the segmentation clock because disruption of this mechanism results in an extended period of zebrafish somitogenesis. It has thus been suggested that collective control of this period via delayed coupling may be a general feature of biological clocks. However, the mechanism by which synchronized oscillation is regulated in the mouse PSM remains to be elucidated.

\section{TRANSLATION OF CLOCK INFORMATION}

As predicted by the clock and wavefront model, the clock (temporal) information must be translated into spatial information to generate a morphologically distinct somite. In zebrafish embryos, it has been suggested that the function of Notch signaling is only to synchronize the oscillations among PSM cells, and that this pathway has no other function during segmentation (Horikawa et al. 2006; Ozbudak and Pourquie 2008). However, Notch acts as an important output signal of the segmentation clock in mouse somitogenesis. In mice, the Notch signal wave travels in a posterior to anterior direction and stops once it reaches the wavefront where FGF and Wnt signals are below a threshold level (Oginuma et al. 2008). As a result, a segmentation program is initiated through the activation of a gene encoding the transcription factor Mesp2, the expression of which oscillates in the anterior PSM as a response to the segmentation clock (Morimoto et al. 2005).

\subsection{Translating Oscillations into Segments in the Wavefront}

The mechanism involved in the transcriptional activation of Mesp2 is directly involved in the mechanism by which temporal clock information is translated into spatial patterning. The analyses of factors involved in the dynamic changes to the Mesp2 expression pattern have revealed that the timing of Mesp 2 activation depends on Notch activity, whereas the positioning of the expression domain is defined by both Tbx6 and FGF signaling (Yasuhiko et al. 2006; Oginuma et al. 2008). The anterior border of the Mesp2 expression domain accords with the anterior border of Tbx6, where Mesp2 transcription is triggered on Notch activation. However, once Mesp2 is activated and translated into its protein product, it destabilizes Tbx6 protein expression (Fig. 7B). The downstream target genes Ripply1/2 may be responsible for the degradation of Tbx6 protein because knocking out these genes results in the anterior expansion of Tbx6 (Takahashi et al. 2010). Thus, once Mesp2 is expressed, the next anterior border of Tbx6 expression is defined, which becomes the next somite border. Mesp2 is expressed as a stripe in the anterior part of the Tbx6 expression domain of about one somite in length. The question then arises as to how the posterior border of Mesp2 expression is defined. Intriguingly, the posterior limit accords with the limit of the FGF signaling gradient, which shows its highest concentration at the tail bud. In the absence of FGF signaling, the Mesp2 expression domain shifts into the posterior PSM, indicating that Mesp2 expression is suppressed in the posterior PSM via FGF. In addition, Wnt signaling may also work in conjunction with FGF to define the Mesp2 expression domain. In a mouse embryo that shows constitutive Wnt activity (activated $\beta$-catenin), the PSM region is extended anteriorly and the oscillation of clock genes such as $L-f n g$ persists for longer in the extended PSM, which is accompanied by the additional formation of Mesp2 stripes (Aulehla et al. 2008).

The evidence shows therefore that both FGF and Wnt are factors responsible for defining the maturation wavefront that facilitates a proper segmentation process. However, the molecular identity of the wavefront has long been a controversial issue. Initially, Fgf8 was proposed to encode 

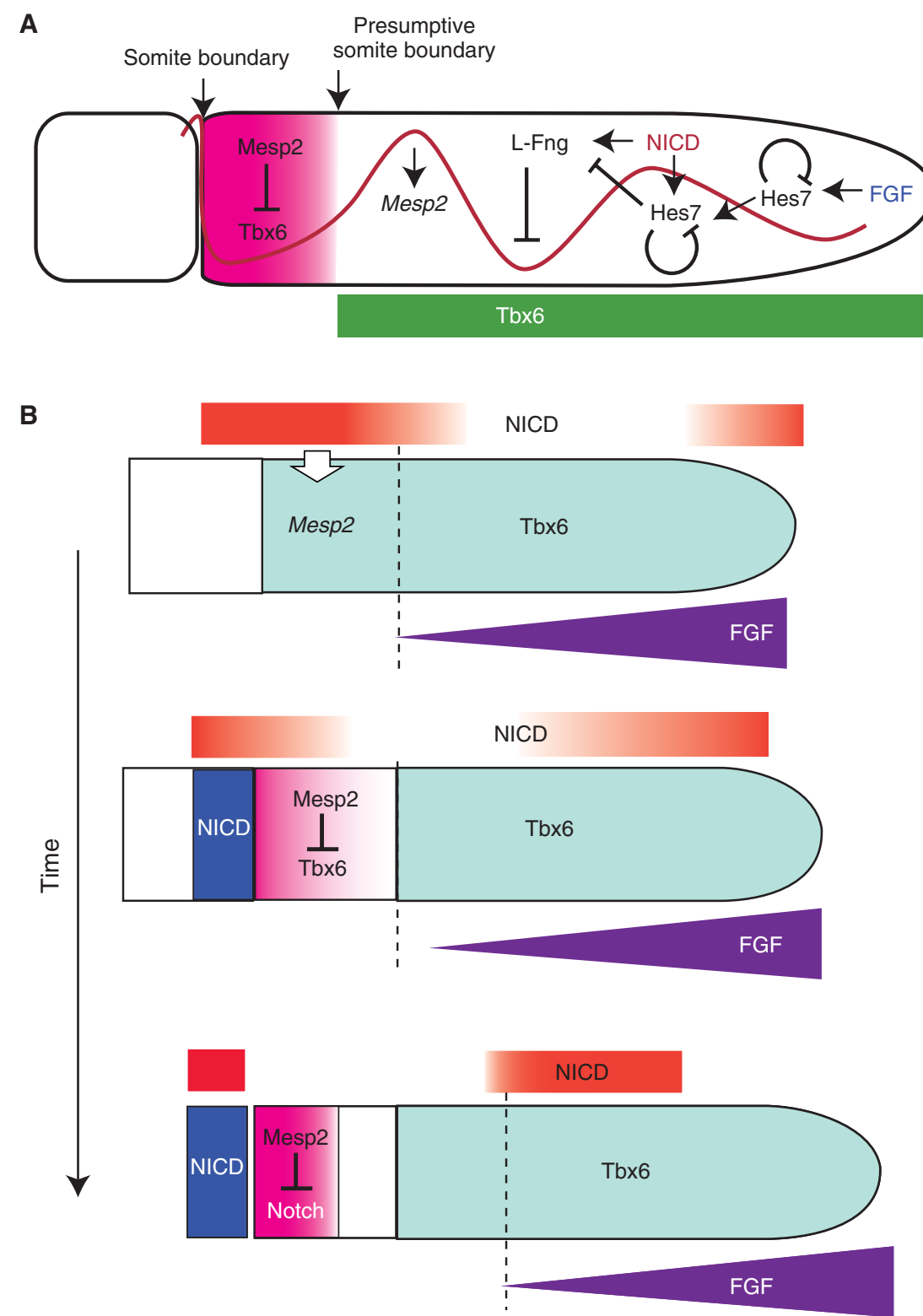

Figure 7. The mechanism of segment border formation. (A) A summary of the clock regulation leading to Mesp2 activation on Notch signaling. $(B)$ A detailed depiction of the interplay between Mesp2 and Tbx6, which is required for segmental border formation. Mesp 2 is activated in cells expressing Tbx6 and receiving a high level of Notchsignaling activity in the absence of FGF signaling (spanning one somite length). Once Mesp2 protein is produced, Tbx6 protein is quickly degraded and a new Tbx6 anterior border is thereby established. Because Notch intracellular domain (NICD) signals move anteriorly, a Mesp2 expression gradient will be generated and its protein expression domain ultimately restricted to the rostral compartment of a somite. Mesp2 also has the ability to repress the Notchsignaling pathway and rostral-caudal polarity is established via the rostrally restricted function of Mesp2.

wavefront activity because experimental manipulation of FGF8 levels caused corresponding shifts in the position of the determination front in cultured chick and zebrafish embryos. However, mouse embryos lacking Fgf8 in the PSM still undergo somitogenesis (Perantoni et al. 2005). Mice homozygous for null mutations in other FGF ligand genes (Fgf3, Fgf5, Fgf15, Fgf17, and Fgf18) also show no early somitogenesis defects, or die before somitogenesis initiates (Fgf4) (Itoh and Ornitz 2008). Wnt has also been proposed to contribute to wavefront activity, because the manipulation of canonical Wnt signaling also causes corresponding shifts in the determination front (Aulehla et al. 2003; Aulehla et al. 2008). However, in Wnt loss-of-function embryos, FGF signaling is also affected. Thus, the 
observed somitogenesis defects may be primarily owing to the loss of Wnt signaling or to secondary effects on FGF signaling. To better understand the actual role of FGF signaling in somitogenesis, a conditional strategy was used to inactivate both Fgf4 and Fgf8 in the PSM. This resulted in dramatic shifts in the determination front and the premature differentiation of the PSM (Naiche et al. 2011). Moreover, the restoration of Wnt signaling to these mutants did not restore the determination front, demonstrating that these two FGFs constitute the proposed wavefront activity that maintains the PSM in an undifferentiated state.

\subsection{The Mechanism of Segmental Border Formation}

The segmental border is positioned through the cooperative function of Tbx6 and Mesp2. However, the nature of how the morphological segregation of the somite is regulated was a crucial question that remained. The anterior border of the segmented somite is perfectly matched with the Mesp2 expression domain. Several target genes of Mesp2 have now been identified, including L-fng, EphA4, and Ripply2 (Morimoto et al. 2005; Nakajima et al. 2006; Morimoto et al. 2007). The transcription of L-fng is under the strict control of Notch signaling in the posterior PSM, but subsequently comes under the control of Mesp2 in the anterior PSM (Morimoto et al. 2005). Because Notch activity can be repressed by L-fng function, it was reasonable to predict that L-fng represses Notch activity in the Mesp2-expressing domain and forms a boundary for the next presumptive somite. This idea was challenged, however, by the impact on somite boundary formation by the uniform expression of NICD in the entire PSM and somitic region (Feller et al. 2008). These results indicated that somite boundaries are generated even in the absence of an NICD border, although they are irregularly shaped and of variable size, and the resulting somites are completely caudalized. This result is further supported by the results of rescue experiments using transgenic mice that express L-fng under the control of Hes7 in the absence of endogenous L-fng expression (L-fng-null mouse) in which the NICD boundary was not generated in the presumptive segmental border (Oginuma et al. 2010). Nevertheless, the segmented somites were found to be normally generated, indicating that L-fng under the control of Mesp2 is dispensable for somite border formation. This being the case, the identity of the event that is actually required for segmental border formation downstream from Mesp2 was a key issue to be resolved. One candidate protein is EphA4, a transmembrane protein kinase, implicated in the formation of the repulsive response between cells via its interaction with ephrin expressed in juxtaposed cells (Fig. 8). Although loss-of- function experiments in the mouse have thus far shown no direct evidence for positive involvement of any particular Eph or ephrin molecule in segmental border formation, the ephrin reverse signaling pathway that activates on EphA binding was implicated in this process in chick (Watanabe et al. 2009).

\subsection{The Mechanism of Somite Patterning (Rostro-Caudal Polarity)}

One of major features of the segmented somite is its compartmentalization into rostral and caudal parts, which is accompanied by differential gene expression patterns and lineage restriction on differentiation. This compartmentalization is required for the segmental patterning of spinal cord development because the somite compartment contributes to the pathway selection of neural crest cells. How this intrasomitic patterning is established during somitogenesis then became an important question. It is now clear that Notch-signaling activity is a required determinant of the caudal identity of the somite and underlies why embryos that ectopically express active Notch in the entire PSM show completely caudalized somite properties (Feller et al. 2008). A similar phenotype is also observed in Mesp2null embryos (Saga et al. 1997). Based on the fact that Mesp2 expression is finally restricted to the rostral compartment of a somite, it appears that Mesp2 suppresses Notch activity in the rostral compartment (Takahashi et al. 2000). Initially it was thought that L-fng induced by Mesp2 is involved in the suppression of NICD formation in the rostral compartment. However, as mentioned above, the functional significance of L-fng in this regard has been discounted. Recently, the instructive role of Mesp2 in the suppression of Notch signaling was revealed in analyses of a knockin mouse containing a dominant-negative form of RBP-jk, the mediator of canonical Notch signaling in the Mesp2 locus (Sasaki et al. 2011). The resulting phenotype was quite surprising because almost all of the defects observed in the Mesp2-null embryo were completely rescued in the DN-RBP-jk knockin mouse. A subsequent study indicated that Mesp2 suppresses Notch activity by destabilizing Mastermind, one of the core components of the nuclear NICD complex (Fig. 8) (Sasaki et al. 2011).

\section{THE MECHANISM TO INITIATE AND TERMINATE CYCLIC GENE EXPRESSION: HOW IS THE SOMITE NUMBER DETERMINED?}

Each vertebrate species has a defined number of somites and so it was of central importance to determine how the somite number is controlled, beginning with an understanding of how the clock system is set up to start somite formation. 
A

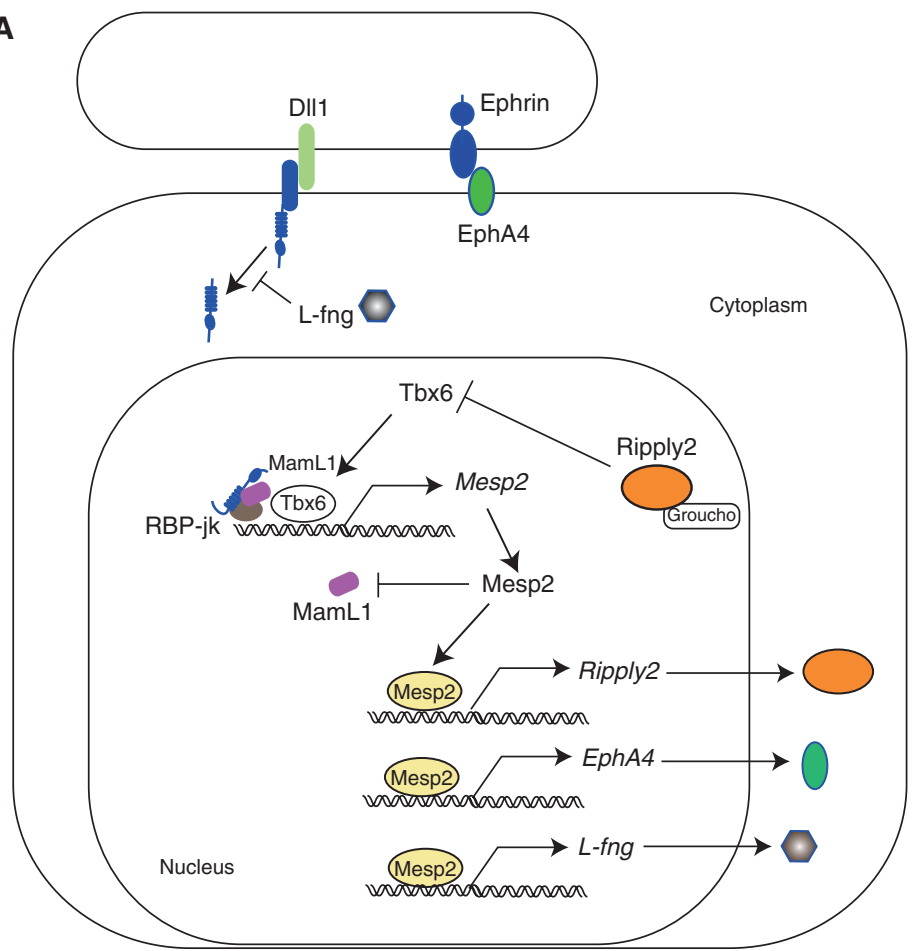

B

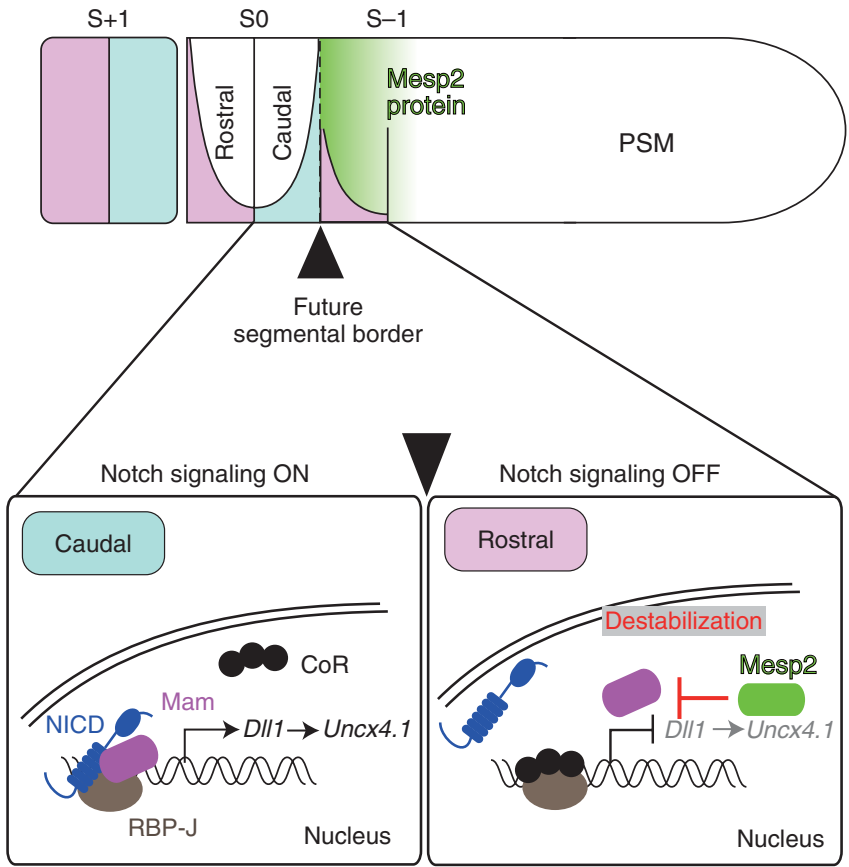

Figure 8. Genetic pathways involved in the regulation of the Mesp2 pathway. (A) Mesp2 expression is activated by Notch signaling and Tbx6. Mesp2 then activates its downstream target genes such as Ripply2, EphA4, and L-fng. Ripply2 is involved in the suppression of Tbx6, which also leads to the suppression of Mesp2 transcription. EphA4 is implicated in the segregation process in the segmental border. L-fng acts on the Notch receptor, resulting in the repression of NICD. Mesp2 also acts on Maml1 to destabilize this protein. (B) The molecular mechanism of rostralcaudal patterning. Notch activity is required to confer caudal property on a somite. In the rostral compartment, Notch activation is suppressed by a Mesp2 function that destabilizes MamL1. S + 1, somite number 1; S0, forming somite; $\mathrm{S}-1$, somite number - 1; PSM, presomitic mesoderm, CoR, transcriptional repressor complex; Mam, mastermindlike proteins. 
In the primitive streak before the formation of somites, strong FGF activity and Tbx6 expression are observed in the entire streak. On streak elongation, an FGF gradient is produced along the AP axis. Notch signal oscillation then appears to commence after a specifically determined period. Once Notch activity oscillation becomes obvious, the first Mesp2 stripe emerges in a 7.5 days postcoitum (dpc) embryo (Oginuma et al. 2008). In principle, somites continue to be formed as long as the PSM acts as a reservoir that supplies new cells. Thus, the number of somites will depend on the PSM life span during embryogenesis, defined by the balance between the speed of somitogenesis and the speed of axis elongation. If the speed of somitogenesis is faster than the speed of axis elongation, then the PSM will shrink quickly and presumably, somitogenesis will arrest when the PSM is finally exhausted. Conversely, if the speed of axis elongation is faster than or equal to the speed of somitogenesis, the PSM size will theoretically increase or remain steady and an indefinite number of segments will be added until the end. The speed of somitogenesis progression therefore essentially depends on the parameters that control the regression speed of the wavefront, and hence on the rate of decay of the Wnt and FGF signals. In contrast, the speed of axis elongation depends on the proliferation rate in the tail bud, which may also depend on FGF and Wnt signals, but likely involves other as yet unknown factors. The mechanism by which the PSM stem cell system is regulated during embryogenesis remains an attractive issue to be solved in the near future.

\section{CONCLUDING REMARKS}

The mechanisms leading to the formation of the somite have long fascinated many researchers because they provide an ideal model system for both mathematicians and developmental biologists. Extensive analyses using mainly the mouse and zebrafish model animals, and with the adoption of mathematical modeling, we now understand how the metameric formation of somites occurs via the clock mechanism operating in unsegmented immature PSM cells. The conserved Notch-signaling pathway and the negative feedback mechanism of the Hes family of transcriptional repressors take central roles in this process. Another factor, Mesp2, plays a crucial role in the translation of clock information into the spatial patterning of the somites. However, there are several important aspects of this system that remain elusive. One is the significance of the oscillating components of the Wnt and FGF signaling pathways. Mathematical models and some experimental evidence have indicated that these are integral parts of the clock system. However, the zebrafish appears not to use such processes to control its segmentation clock. There could be some evolutional reasons for this. Each animal has its own clock period and somite numbers. Somitogenesis is an integral part of embryogenesis and must be coupled with the timing of other developmental stages. The collective behavior of PSM cells is a hallmark of somitogenesis. However, we still do not understand the molecular mechanism leading to the synchronized oscillation that underpins mouse somitogenesis. Mouse genetics has proved to be a strong tool for uncovering the molecular events that govern embryogenesis. However, new imaging technologies are needed in addition to genetic manipulations to visualize and quantify the molecular events that underlie somitogenesis.

\section{REFERENCES}

Aulehla A, Wehrle C, Brand-Saberi B, Kemler R, Gossler A, Kanzler B, Herrmann BG. 2003. Wnt3a plays a major role in the segmentation clock controlling somitogenesis. Dev Cell 4: 395-406.

Aulehla A, Wiegraebe W, Baubet V, Wahl MB, Deng C, Taketo M, Lewandoski M, Pourquie O. 2008. A $\beta$-catenin gradient links the clock and wavefront systems in mouse embryo segmentation. Nat Cell Biol 10: 186-193.

Bessho Y, Sakata R, Komatsu S, Shiota K, Yamada S, Kageyama R. 2001a. Dynamic expression and essential functions of Hes7 in somite segmentation. Genes Dev 15: 2642-2647.

Bessho Y, Sakata R, Komatsu S, Shiota K, Yamada S, Kageyama R. 2001 b. Dynamic expression and essential functions of Hes7 in somite segmentation. Genes Dev 15: 2642-2647.

Bessho Y, Hirata H, Masamizu Y, Kageyama R. 2003. Periodic repression by the bHLH factor Hes7 is an essential mechanism for the somite segmentation clock. Genes Dev 17: 1451-1456.

Brand-Saberi B, Christ B. 2000. Evolution and development of distinct cell lineages derived from somites. Curr Top Dev Biol 48: 1-42.

Brent AE, Tabin CJ. 2002. Developmental regulation of somite derivatives: Muscle, cartilage and tendon. Curr Opin Genet Dev 12: 548-557.

Bronner-Fraser M. 1986. Analysis of the early stages of trunk neural crest migration in avian embryos using monoclonal antibody HNK-1. Dev Biol 115: 44-55.

Carapuco M, Novoa A, Bobola N, Mallo M. 2005. Hox genes specify vertebral types in the presomitic mesoderm. Genes Dev 19: 2116-2121.

Chapman DL, Papaioannou VE. 1998. Three neural tubes in mouse embryos with mutations in the T-box gene Tbx6. Nature 391: 695-697.

Cole SE, Levorse JM, Tilghman SM, Vogt TF. 2002. Clock regulatory elements control cyclic expression of Lunatic fringe during somitogenesis. Dev Cell 3: 75-84.

Conlon RA, Reaume AG, Rossant J. 1995. Notch1 is required for the coordinate segmentation of somites. Development 121: 1533-1545.

Cooke J, Zeeman EC. 1976. A clock and wavefront model for control of the number of repeated structures during animal morphogenesis. J Theor Biol 58: 455-476.

Dale JK, Maroto M, Dequeant ML, Malapert P, McGrew M, Pourquie O. 2003. Periodic notch inhibition by lunatic fringe underlies the chick segmentation clock. Nature 421: 275-278.

de la Pompa JL, Wakeham A, Correia KM, Samper E, Brown S, Aguilera RJ, Nakano T, Honjo T, Mak TW, Rossant J, et al. 1997. Conservation of the Notch signalling pathway in mammalian neurogenesis. Development 124: 1139-1148.

Dequeant ML, Pourquie O. 2008. Segmental patterning of the vertebrate embryonic axis. Nat Rev Genet 9: 370-382.

Dequeant ML, Glynn E, Gaudenz K, Wahl M, Chen J, Mushegian A, Pourquie O. 2006. A complex oscillating network of signaling genes underlies the mouse segmentation clock. Science 314: 1595-1598. 
Deschamps J, van Nes J. 2005. Developmental regulation of the Hox genes during axial morphogenesis in the mouse. Development 132: $2931-2942$.

Donoviel DB, Hadjantonakis AK, Ikeda M, Zheng H, Hyslop PS, Bernstein A. 1999. Mice lacking both presenilin genes exhibit early embryonic patterning defects. Genes Dev 13: 2801-2810.

Evrard YA, Lun Y, Aulehla A, Gan L, Johnson RL. 1998. Lunatic fringe is an essential mediator of somite segmentation and patterning. Nature 394: 377-381.

Fan CM, Tessier-Lavigne M. 1994. Patterning of mammalian somites by surface ectoderm and notochord: Evidence for sclerotome induction by a hedgehog homolog. Cell 79: 1175-1186.

Feller J, Schneider A, Schuster-Gossler K, Gossler A. 2008. Noncyclic Notch activity in the presomitic mesoderm demonstrates uncoupling of somite compartmentalization and boundary formation. Genes Dev 22: $2166-2171$.

Furumoto TA, Miura N, Akasaka T, Mizutani-Koseki Y, Sudo H, Fukuda K, Maekawa M, Yuasa S, Fu Y, Moriya H, et al. 1999. Notochorddependent expression of MFH1 and PAX1 cooperates to maintain the proliferation of sclerotome cells during the vertebral column development. Dev Biol 210: 15-29.

Goldstein RS, Kalcheim C. 1992. Determination of epithelial halfsomites in skeletal morphogenesis. Development 116: 441-445.

Gomez C, Pourquie O. 2009. Developmental control of segment numbers in vertebrates. J Exp Zool B Mol Dev Evol 312: 533-544.

Gomez C, Ozbudak EM, Wunderlich J, Baumann D, Lewis J, Pourquie O. 2008. Control of segment number in vertebrate embryos. Nature 454: $335-339$.

Henry CA, Urban MK, Dill KK, Merlie JP, Page MF, Kimmel CB, Amacher SL. 2002. Two linked hairy/Enhancer of split-related zebrafish genes, her 1 and her7, function together to refine alternating somite boundaries. Development 129: 3693-3704.

Hirata H, Bessho Y, Kokubu H, Masamizu Y, Yamada S, Lewis J, Kageyama R. 2004. Instability of Hes7 protein is crucial for the somite segmentation clock. Nat Genet 36: 750-754.

Holley SA, Geisler R, Nusslein-Volhard C. 2000. Control of her1 expression during zebrafish somitogenesis by a delta-dependent oscillator and an independent wave-front activity. Genes Dev 14: 1678-1690.

Horikawa K, Ishimatsu K, Yoshimoto E, Kondo S, Takeda H. 2006. Noiseresistant and synchronized oscillation of the segmentation clock. $\mathrm{Na}$ ture 441: 719-723.

Hrabe de Angelis M, McIntyre J III, Gossler A. 1997. Maintenance of somite borders in mice requires the Delta homologue DII1. Nature 386: $717-721$

Iimura T, Pourquie O. 2006. Collinear activation of Hoxb genes during gastrulation is linked to mesoderm cell ingression. Nature 442: 568-571.

Iimura T, Yang X, Weijer CJ, Pourquie O. 2007. Dual mode of paraxial mesoderm formation during chick gastrulation. Proc Natl Acad Sci 104: $2744-2749$.

Itoh N, Ornitz DM. 2008. Functional evolutionary history of the mouse Fgf gene family. Dev Dyn 237: 18-27.

Jiang YJ, Aerne BL, Smithers L, Haddon C, Ish-Horowicz D, Lewis J. 2000. Notch signalling and the synchronization of the somite segmentation clock. Nature 408: 475-479.

Kawamura A, Koshida S, Hijikata H, Sakaguchi T, Kondoh H, Takada S. 2005. Zebrafish hairy/enhancer of split protein links FGF signaling to cyclic gene expression in the periodic segmentation of somites. Genes Dev 19: $1156-1161$.

Keynes RJ, Stern CD. 1988. Mechanisms of vertebrate segmentation. Development 103: 413-429.

Kusumi K, Sun ES, Kerrebrock AW, Bronson RT, Chi DC, Bulotsky MS, Spencer JB, Birren BW, Frankel WN, Lander ES. 1998. The mouse pudgy mutation disrupts Delta homologue Dll3 and initiation of early somite boundaries. Nat Genet 19: 274-278.

Lewis J. 2003. Autoinhibition with transcriptional delay: A simple mechanism for the zebrafish somitogenesis oscillator. Curr Biol 13: 13981408 .
Masamizu Y, Ohtsuka T, Takashima Y, Nagahara H, Takenaka Y, Yoshikawa K, Okamura H, Kageyama R. 2006. Real-time imaging of the somite segmentation clock: Revelation of unstable oscillators in the individual presomitic mesoderm cells. Proc Natl Acad Sci 103: 13131318.

McMahon JA, Takada S, Zimmerman LB, Fan CM, Harland RM, McMahon AP. 1998. Noggin-mediated antagonism of BMP signaling is required for growth and patterning of the neural tube and somite. Genes Dev 12: 1438-1452.

Morimoto M, Takahashi Y, Endo M, Saga Y. 2005. The Mesp2 transcription factor establishes segmental borders by suppressing Notch activity. Nature 435: 354-359.

Morimoto M, Sasaki N, Oginuma M, Kiso M, Igarashi K, Aizaki K, Kanno J, Saga Y. 2007. The negative regulation of Mesp2 by mouse Ripply2 is required to establish the rostro-caudal patterning within a somite. Development 134: 1561-1569.

Naiche LA, Holder N, Lewandoski M. 2011. FGF4 and FGF8 comprise the wavefront activity that controls somitogenesis. Proc Natl Acad Sci 108: 4018-4023.

Nakajima Y, Morimoto M, Takahashi Y, Koseki H, Saga Y. 2006. Identification of Epha4 enhancer required for segmental expression and the regulation by Mesp2. Development 133: 2517-2525.

Niwa Y, Masamizu Y, Liu T, Nakayama R, Deng CX, Kageyama R. 2007. The initiation and propagation of Hes7 oscillation are cooperatively regulated by Fgf and notch signaling in the somite segmentation clock. Dev Cell 13: 298-304.

Oates AC, Ho RK. 2002. Hairy/E(spl)-related (Her) genes are central components of the segmentation oscillator and display redundancy with the Delta/Notch signaling pathway in the formation of anterior segmental boundaries in the zebrafish. Development 129: 2929-2946.

Oginuma M, Niwa Y, Chapman DL, Saga Y. 2008. Mesp2 and Tbx6 cooperatively create periodic patterns coupled with the clock machinery during mouse somitogenesis. Development 135: 2555-2562.

Oginuma M, Takahashi Y, Kitajima S, Kiso M, Kanno J, Kimura A, Saga Y. 2010. The oscillation of Notch activation, but not its boundary, is required for somite border formation and rostral-caudal patterning within a somite. Development 137: 1515-1522.

Oyama T, Harigaya K, Sasaki N, Okamura Y, Kokubo H, Saga Y, Hozumi K, Suganami A, Tamura Y, Nagase T, et al. 2011. Mastermind-like 1 (MamL1) and mastermind-like 3 (MamL3) are essential for Notch signaling in vivo. Development 138: 5235-5246.

Ozbudak EM, Pourquie O. 2008. The vertebrate segmentation clock: The tip of the iceberg. Curr Opin Genet Dev 18: 317-323.

Palmeirim I, Henrique D, Ish-Horowicz D, Pourquie O. 1997. Avian hairy gene expression identifies a molecular clock linked to vertebrate segmentation and somitogenesis. Cell 91: 639-648.

Perantoni AO, Timofeeva O, Naillat F, Richman C, Pajni-Underwood S, Wilson C, Vainio S, Dove LF, Lewandoski M. 2005. Inactivation of FGF8 in early mesoderm reveals an essential role in kidney development. Development 132: 3859-3871.

Pourquie O. 2003. Vertebrate somitogenesis: A novel paradigm for animal segmentation? Int J Dev Biol 47: 597-603.

Saga Y, Takeda H. 2001. The making of the somite: Molecular events in vertebrate segmentation. Nat Rev Genet 2: 835-845.

Saga Y, Hata N, Koseki H, Taketo MM. 1997. Mesp2: A novel mouse gene expressed in the presegmented mesoderm and essential for segmentation initiation. Genes Dev 11: 1827-1839.

Sasaki N, Kiso M, Kitagawa M, Saga Y. 2011. The repression of Notch signaling occurs via the destabilization of mastermind-like 1 by Mesp2 and is essential for somitogenesis. Development 138: 55-64.

Shi S, Stanley P. 2006. Evolutionary origins of Notch signaling in early development. Cell Cycle 5: 274-278.

Takahashi Y, Koizumi K, Takagi A, Kitajima S, Inoue T, Koseki H, Saga Y. 2000. Mesp2 initiates somite segmentation through the Notch signalling pathway. Nat Genet 25: 390-396.

Takahashi J, Ohbayashi A, Oginuma M, Saito D, Mochizuki A, Saga Y, Takada S. 2010. Analysis of Ripply1/2-deficient mouse embryos reveals a 
mechanism underlying the rostro-caudal patterning within a somite. Dev Biol 342: 134-145.

Takashima Y, Ohtsuka T, Gonzalez A, Miyachi H, Kageyama R. 2011. Intronic delay is essential for oscillatory expression in the segmentation clock. Proc Natl Acad Sci 108: 3300-3305.

Takemoto T, Uchikawa M, Yoshida M, Bell DM, Lovell-Badge R, Papaioannou VE, Kondoh H. 2011. Tbx6-dependent Sox2 regulation determines neural or mesodermal fate in axial stem cells. Nature 470: 394-398.

Teillet MA, Kalcheim C, Le Douarin NM. 1987. Formation of the dorsal root ganglia in the avian embryo: Segmental origin and migratory behavior of neural crest progenitor cells. Dev Biol 120: 329-347.

Watanabe T, Sato Y, Saito D, Tadokoro R, Takahashi Y. 2009. EphrinB2 coordinates the formation of a morphological boundary and cell epithelialization during somite segmentation. Proc Natl Acad Sci 106: $7467-7472$.

Wellik DM. 2007. Hox patterning of the vertebrate axial skeleton. Dev Dyn 236: 2454-2463.

Wellik DM, Capecchi MR. 2003. Hox10 and Hox11 genes are required to globally pattern the mammalian skeleton. Science 301: 363-367.

Yamaguchi TP, Takada S, Yoshikawa Y, Wu N, McMahon AP. 1999. T (Brachyury) is a direct target of Wnt3a during paraxial mesoderm specification. Genes Dev 13: 3185-3190.

Yasuhiko Y, Haraguchi S, Kitajima S, Takahashi Y, Kanno J, Saga Y. 2006. Tbx6-mediated Notch signaling controls somite-specific Mesp2 expression. Proc Natl Acad Sci 103: 3651-3656.

Zhang N, Gridley T. 1998. Defects in somite formation in lunatic fringedeficient mice. Nature 394: 374-377. 


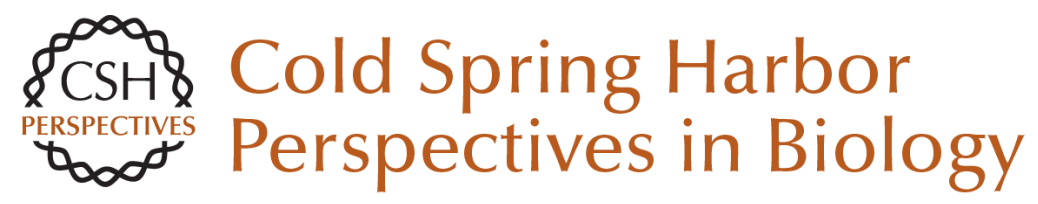

\title{
The Synchrony and Cyclicity of Developmental Events
}

\author{
Yumiko Saga \\ Cold Spring Harb Perspect Biol 2012; doi: 10.1101/cshperspect.a008201
}

Subject Collection Mammalian Development

The Dynamics of Morphogenesis in the Early Mouse Embryo

Jaime A. Rivera-Pérez and Anna-Katerina Hadjantonakis

microRNAs as Developmental Regulators Kathryn N. Ivey and Deepak Srivastava

Development of the Endochondral Skeleton Fanxin Long and David M. Ornitz

Adipogenesis Kelesha Sarjeant and Jacqueline M. Stephens

Molecular Mechanisms of Inner Ear Development Doris K. Wu and Matthew W. Kelley

Polarity in Mammalian Epithelial Morphogenesis Julie Roignot, Xiao Peng and Keith Mostov

Eye Development and Retinogenesis Whitney Heavner and Larysa Pevny

Primordial Germ Cells in Mice Mitinori Saitou and Masashi Yamaji
Cell Division Modes and Cleavage Planes of Neural Progenitors during Mammalian Cortical Development

Fumio Matsuzaki and Atsunori Shitamukai

Blood and Lymphatic Vessel Formation Victoria L. Bautch and Kathleen M. Caron

Transcriptional Networks in Liver and Intestinal

Development Karyn L. Sheaffer and Klaus H. Kaestner

Pluripotency in the Embryo and in Culture Jennifer Nichols and Austin Smith

Signaling and Transcriptional Networks in Heart Development and Regeneration Benoit G. Bruneau

Signals and Switches in Mammalian Neural Crest Cell Differentiation Shachi Bhatt, Raul Diaz and Paul A. Trainor

Hematopoiesis Michael A. Rieger and Timm Schroeder

Intercellular Interactions, Position, and Polarity in Establishing Blastocyst Cell Lineages and Embryonic Axes Robert O. Stephenson, Janet Rossant and Patrick P.L. Tam

For additional articles in this collection, see http://cshperspectives.cshlp.org/cgi/collection/

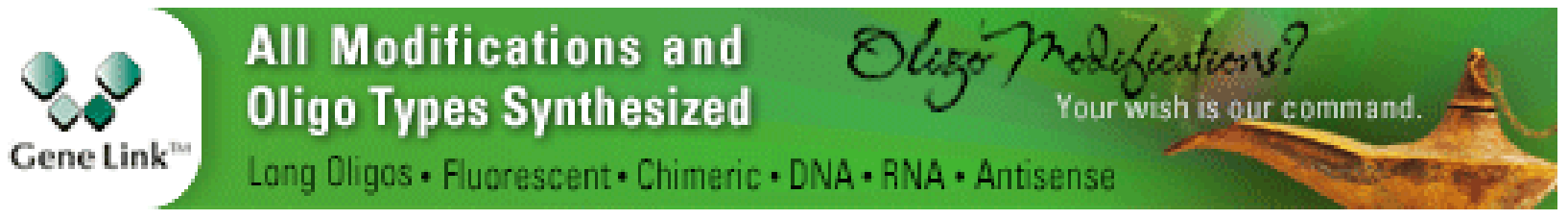

Copyright @ 2012 Cold Spring Harbor Laboratory Press; all rights reserved 